\title{
A History of Shoulder Surgery
}

\author{
S. Iqbal*, U. Jacobs, A. Akhtar, R.J. Macfarlane and M. Waseem
}

Salford Royal NHS Foundation Trust, Stott Lane, Salford, M6 8HD, UK

\begin{abstract}
Shoulder surgery has emerged from being a marginalised sub-speciality to being an area of much research and advancement within the last seventy years. This has been despite the complexity of the joint, and success majorly rests on parallel development of biomedical technology. This article looks at the past and present of shoulder surgery and discusses future directions in the speciality.
\end{abstract}

Keywords: Orthopaedic surgery, shoulder surgery, shoulder instability, proximal humeral fractures, rotator cuff, arthroplasty, arthroscopy, biological therapy, stem cell therapy.

\section{INTRODUCTION}

Shoulder surgery has relatively recently been recognized as a separate orthopaedic sub-speciality. The first Symposium on Surgery of the Shoulder Region was held in Montreal in 1963, and the first International Conference on Surgery of the Shoulder was hosted in London no earlier than in 1980. Improved understanding of the basic sciences underpinning the shoulder and its associated pathologies, advancement in surgical technique, implant design and manufacture have made major contributions to this rapidly expanding subspecialty. This article aims to review the major landmarks in the history of shoulder orthopaedics, and discusses the directions in which it is likely to progress in the future.

\section{SHOULDER INSTABILITY}

The first recorded references to shoulder manipulation are indeed ancient. Egyptian hieroglyphs dated 3000 years earlier, pictorially depict a leverage method of shoulder reduction. The method was re-introduced in the 1870 as a painless technique by Theodor Kocher, but is now obsolete because of the likelihood of serious complications.

Around $400 \mathrm{BC}$, Hippocrates, the father of Western medicine introduced the traction method to reduce the shoulder. The patient lay supine whilst the physician standing on the patient's affected side held the arm and applied traction. The stockinged foot of the physician placed in the axilla served as counter traction. This technique was detailed in the Hippocratic Corpus, and as it remained the primary medical text for centuries so did the method.

The first shoulder arthrodesis was performed for a case of recurrent shoulder dislocation in the 1800 s by the Czech surgeon, Eduard Albert, who was also the first to use the term arthrodesis.

In the 1890s, the understanding of the unstable shoulder was elucidated by the work of two researchers, Broca and

*Address correspondence to this author at the Salford Royal NHS Foundation Trust, Stott Lane, Salford, M6 8HD, UK; Tel: 0044 (0) 787216 4006; E-mail: drshoaibiqbal@gmail.com
Hartman who described the detailed anatomy of the glenohumeral ligament complex and its association with chronic instability of the shoulder [1].

In 1906, Perthes in Germany [2] and a few years later, Bankart in the UK ascertained that the detachment of the labrum caused instability of the shoulder and emphasized reattachment of the labrum to stabilize the joint [3]. Perthes' operative technique, using bone clips and transglenoidalstitches is used with some modification up until this day. In 1961, Herbert Moseley published a well-illustrated and highly referenced work on recurrent dislocation [4] detailing the anatomy and pathology of various types of dislocations. Mosley suggested the use of extra-articular vitallium prosthesis to avoid recurrences.

Carter Rowe wrote extensively on instability and his published work on the subject spanned three decades. He studied prognosis in traumatic anterior dislocations, and showed that chances of recurrence were much higher $(92 \%)$ in the second decade as compared to $12 \%$ in those above the age of fifty, establishing that the age at primary shoulder dislocation was the single most important prognostic factor [5].

In a 1980 article, the prominent American shoulder surgeon Charles Neer, along with Foster, published his work on multidirectional instability. He noted that inferior instability was a hallmark of multidirectional instability and developed the humeral-based capsular shift to eliminate the redundant inferior pouch $[6,7]$.

In 1987, Dr Neer described that the diagnosis of locked posterior dislocations required an adequate axillary view, and that the physical examination in this setting would demonstrate a loss of external rotation [8].

By the beginning of the 20th century many different operative techniques were being used to correct instability of the shoulder, with some 150 open and arthroscopic procedures in use for the correction of anterior dislocation alone. Two most popular procedures included the Latarjet [9] and the Bristow-Helfet [10], which were devised in 1954 and 1958 respectively. Latarjet was the first to transplant the coracoid process to the neck of the scapula through the 
subscapularis tendon. Mead and Sweeney in 1964 [11], and May in 1970 [12], described a modification of the BristowHelfet procedure that consisted of fixing the coracoid bone block to the anterior glenoid rim with a screw. Arthroscopic Latarjet procedure has been tried successfully in recent years $[13,14]$. This procedure offers many advantages, including a good exposure of the glenoid surface and a secure extraarticular bone block position. Moreover, if the capsule and the labrum are not resected, these can be re-attached. This, though is a complex procedure and requires expertise and technical skill [15].

\section{PROXIMAL HUMERUS FRACTURES}

In proximal humeral fractures, knowledge of the arterial supply of the epiphysis is essential, as avascular necrosis of the humeral head remains a concern. Cadaveric arterial perfusion studies by Laing [16] in 1956 established that the main arterial supply to the humeral head is from the arcuate artery, a branch the anterior humeral circumflex artery. Later, in 1990, Geber and colleagues demonstrated a rich extra-osseous anastomosis, with the anterior humeral artery being the final common pathway for supply to the head, and the entire articular surface being supplied by the arcuate artery. He highlighted the importance of the posteromedial branch of the posterior humeral circumflex artery, which supplies the posterior aspect of the greater tuberosity [17].

Following a four-part fracture, when the blood supply from the anterior humeral circumflex artery, the greater tuberosity, the lesser tuberosity and any metaphyseal arterial anastomoses has usually been lost, perfusion of the humeral head via the arcuate artery may continue if the head fragment includes part of the medial aspect of the upper part of the neck. Hence Jakob et al. in 1991 reported a low incidence of avascular necrosis of the humeral head in four-part fractures in which the humeral head was impacted and in valgus [18]. He showed that in this type of fracture, the medial aspect of the humeral head is little displaced, and may thus retain its vascularity from the posteromedial vessels. When the medial fracture line is at the junction between the articular surface and the neck this anastomosis will be lost, resulting in avascularity of the head and articular surface.

In 1934, Ernest Codman described fractures of the proximal humerus, classifying them as occurring in the head, greater or lesser tuberosity, and upper shaft and suggesting that if displacement occurred, operative fixation would be required [19]. Neer's classification of proximal humeral fractures reported in 1970 greatly expanded on Codman's work, categorizing fractures according to the segments involved, as two-part, three-part, four-part fractures, fracture dislocations, and head-splitting fractures. He defined significant displacement as being greater than $1 \mathrm{~cm}$, and angulation as more than 45 degrees [20]. His landmark work in this subject and the system of fracture classification that he devised forty years ago remains current till this day. The AO classification for proximal humeral fractures proposed in 1996 [21] is less used than Neer's mainly because of its complexity [22].

Neer, in 1953 became the first to devise a prosthetic humeral head, to replace a native head that had suffered a comminuted fracture [23].

\section{THE SUBACROMIAL SPACE}

The Boston Medical and Surgical Journal in 1911 published an article by Codman, reporting on two successful cases of repair of complete rupture of the supraspinatus tendon [24]. In the article, Codman also identified that most tears occur on the articular side of the tendon. Although John Gregory Smith, as early as 1834, had identified rupture of the rotator cuff during cadaveric dissections at the Hunterian Theatre of Anatomy [25] Codman's was a revolutionary article, because it was the first report of repair of the rotator cuff.

In 1944, Mc Laughlin devised a novel method of reattaching the supraspinatus tendon more proximally than at its usual site on the greater tuberosity in cases of rotator cuff tears [26]. Neer, in the 1970s and later, studied the disturbed mechanics of the subacromialspace and described subacromial impingement as an important factor in the causation of rotator cuff disease. In his 1972 article, he introduced this concept and additionally, reported on anterior acromioplasty, a procedure he had developed to correct impingement [27]. In the following decades, there have been many studies to explore the aetiology of rotator cuff tears. Bigilani et al. studied shapes of the acromion and correlated the hooked type to increased cuff tears [28].

More recently, studies by several authors have led to a modification of Bigilani's classification system, in an effort to objectify the anatomy of the acromion and decrease interobserver variability [29]. Data have shown that overhead athletes have a greater likelihood of developing tears because of the extreme positions of abduction and external rotation. Welch in 1992 described impingement of the under surface of the cuff on the posterosuperiorglenoidlabrum in such athletes [30]. Neer in his 1983 article suggested that degenerative changes may be responsible for impingement. He described the three stages of impingement and observed that the final stage of partial or complete cuff tears occurred in those over 40 years old [31]. It was shown by Petterson and Gentz in 1983, that fifty-four per cent of shoulders with tendon tears had acromioclavicular osteophytes pointing distally, while only $10 \%$ of normal shoulders showed these degenerative osteophytes [32]. In a study on siblings by Gwilym et al, genetic factors were implicated to have a significant role not only in the causation but also in the progression of rotator cuff tears [33].

The operative treatment of subacromial disease still continues to be what Neer had developed 30 years ago: the anterior and lower parts of the acromion, which come in contact with the rotator cuff and the bursa subacromialis and coracoacromial ligament are excised. Initially this used to be performed through an open technique. Nowadays, arthroscopic subacromial decompression (ASD) is standard treatment [34]. Open surgery is reserved for more complicated situations like revision operations [35].

\section{ARTHROPLASTY}

The first shoulder arthroplasty was performed in 1893 by the French surgeon Jules Pean for a case of destruction of the shoulder joint by tuberculosis $[36,37]$. The prosthesis was designed by a dentist, and the humeral stem was made of platinum and leather which articulated with a glenoid made 
of paraffin coated ebonite. It had to be removed after two years of implantation because of chronic infection.

No innovations with prosthetic replacements occurred for the next fifty years, until Neer performed the first hemiarthroplasty for comminuted proximal humerus fracture. This, the first-generation prosthesis was a monoblock implant made of vitallium [23]. In the 1960s, shoulder arthroplasty began to be used for a range of disorders, including osteoarthritis and rheumatoid arthritis, osteonecrosis and humeral head fractures.

Glenoid resurfacing was introduced by Stellbrink in 1976 using polyethylene, to complement Neer's humeral head, and the total shoulder was thus developed [38].

The second generation of prosthesis was introduced in the early 1990's. These were modular, after Neer's principle of closely mimicking normal anatomy. Different sizes of the humeral head and glenoid, and a range of dimensions in the humeral stem were developed to allow better fit and function. An additional characteristic of second-generation designs was a mismatch between the radii of curvature of the humeral head and the glenoid component in order to lessen the occurrence of radiolucent lines at the glenoid component which had been of concern previously [39]. However, the dimensions of the head continued to pose problems of poor fit [22].

The third generation of implants emerged in the 90's, based on the detailed three dimensional anatomy of the proximal humerus. These provided greater conformity, offsetting the head in relation to the axis of the medulla and allowing for variable inclination of the neck [40]. Results with these have been encouraging.

The concept of the reverse shoulder prosthesis was introduced in the 1970 s, primarily to treat rotator cuff tears. Paul M Grammont [41, 42], initially proposed the use of an acromiohumeral prosthesis, which was abandoned due to problems of acromial loosening. Grammont then devised the principle of reverse prosthesis, making a breakthrough by medialising the centre of rotation in a non-anatomic location, thus relying on deltoid function alone, and placing lesser demand on the glenoid. This indeed was a revolution in arthroplasty for cases of deficient rotator cuffs. In 1985, Grammont experimented with the first model, the 'Trompette' using a cemented sphere, which proved successful. The work of Grammont and the development of the DELTA III prosthesis have been fundamental to all subsequent reverse shoulder arthroplasty systems.

\section{ARTHROSCOPY}

Arthroscopic surgery has been one of the biggest orthopaedic advancements of the last century. The first report of shoulder arthroscopy was by Burman in 1931 on cadavers [43]. It was not until 35 years later, that the first clinical use of the procedure was described [44].

The understanding of shoulder disorders and their treatment has advanced significantly in the last few decades as a result of arthroscopy, which has fast progressed from diagnosis to ablative procedures and now to reconstructive surgery. It can be used for the diagnosis and management of shoulder instability, rotator cuff disease, fractures and other soft tissue trauma. A range of procedures for the unstable shoulder, the Bankart repair, capsular shift, and the Latarjet procedure can be performed arthroscopically. With shoulder instabilities, besides tearing of the capsule and the labrum, stretching of the capsule is also responsible for recurrence. With open surgery the tension of the capsule could not be adjusted precisely. Newer arthroscopic techniques aim at removing the redundancy of the capsule with capsular shifts, or thermal or laser induced shrinkage.

Arthroscopic subacromial decompression first performed by Harvard Ellman in 1985 is now considered a routine arthroscopic procedure [45]. New lesions which were previously undiagnosed have been detailed and classified, expanding the differential diagnosis of the painful shoulder. An example is the SLAP (superior labrum anterior and posterior) lesion described by Steve Snyder [46] in overhead athletes. Another is internal impingement of the cuff against the posterosuperior aspect of the labrum during abduction and external rotation, a phenomenon described by Walch et al. in 1991[47]. Many variants such as the Buford complex and biceps variants have also been recognised as anatomical entities.

Techniques for arthroscopic Weaver-Dunn procedures, bone grafting and arthroscopy assisted fracture fixation have recently been developed. A disadvantage is that complication rates are higher when more complex surgery is performed through the scope.

\section{IMAGING}

New advances in imaging have come mainly from continental Europe. Arthography, previously used to image the soft tissues around the shoulder has been replaced in the last 15 years by sonography, which gives reasonable results for the diagnosis of rotator cuff defects [47]. MRI is increasingly used to assess degenerative joint disorders, labral tears, complicated high humeral fractures, rotator cuff disorders, including tears and impingement, joint abnormalities due to trauma, sports and work-related disorders caused by repeated strain, osteomyelitis and tumours and to monitor progress after shoulder surgery [48].

\section{THE FUTURE}

The future of shoulder surgery rests on advancements in instrument and computing technology and in the fields of tissue biology and genetic engineering.

At this point in time, most surgery on the shoulder can be performed arthroscopically. This includes repair of rotator cuff tears, correction of shoulder dislocations, labral tears, acromioclavicular arthritis and proximal biceps pathology. In 2010, Austrian surgeon Werner Anderl reported successful arthroscopic resurfacing of the humerus and development of the trans-humeral glenoid preparation [49]. The arthroscope itself is evolving into a slim 18 gauge needle, and this will make most procedures possible as day cases conducted in the clinic under local anaesthesia with minimal pain and quicker recovery.

Several novel biological agents have shown promising results in animal models and initial clinical studies have also shown short and medium term success in clinical, functional and radiological outcome. In shoulder osteoarthritis, autologous stem cells injected into the joint space can 
generate functional chondrocytes, with regeneration of healthy cartilage within a few weeks. With a potential to replace procedures like sub-acromial decompression, stem cells injected into the torn rotator cuff gradually generate into healthy fibroblasts. Most data is preclinical, but success of stem cell therapy in animal models has been clearly established in recent literature [50].

Other emerging potential intra-articular therapies include IL-1 receptor antagonist which targets interleukin-1 $\beta$, conditioned autologous serum containing a number of antiinflammatory cytokines, botulinum toxin which is antinociceptive and probably anti-inflammatory, and recombinant human BMP-7 (bone morphogenetic protein-7). For each of these therapies, trial data in humans has been published, but more studies are needed to establish that they are safe and effective in the longer term [51]. Till yet, most research on these new modalities has focused on the knee joint, but a study on the use of botulinum toxin in chronic refractory osteoarthritis of the shoulder, has shown promise in terms of pain reduction and improvement in function [52]. Reducing the immunogenicity of these biologicals, so that repairs and reconstruction last long-term remains a challenge for the future.

\section{CONFLICT OF INTEREST}

The authors confirm that this article content has no conflict of interest.

\section{ACKNOWLEDGEMENTS}

Declared none.

\section{REFERENCES}

[1] Broca A, Hartmann H. Contribution à l'étude des luxations de l'épaule (luxationsanciennesetluxationsrécidivantes). Bull Soc Anat 1890; 4: 416-23.

[2] Perthes G. Ueber Operationen beihabitueller Schulterluxation. Dtsch Z Chir 1906; 85: 199-227.

[3] Bankart ASB. Recurrent or habitual dislocation of the shoulder joint. BMJ 1923; 2: 1132-3

[4] Moseley HF. Recurrent dislocation of the shoulder. Montreal: McGillUnivPress 1961

[5] Rowe CR. Prognosis in dislocations of the shoulder. J Bone Joint Surg Am 1956; 38: 957-77.

[6] Neer CS $2^{\text {nd }}$, Foster CR. Inferior capsular shift for involuntary inferior and multidirectional instability of the shoulder: a preliminary report. J Bone Joint Surg Am 1980; 62(6): 897-908

[7] Neer CS, $2^{\text {nd }}$. Involuntary inferior and multidirectional instability of the shoulder: Etiology, recognition, and treatment. Instr Course Lect $1985 ; 34: 232-8$.

[8] Hawkins RJ, Neer CS $2^{\text {nd }}$, Pianta RM, et al. Locked posterior dislocation of the shoulder. J Bone Joint Surg Am, 1987; 69(1): 918.

[9] M. Latarjet. Traitement de la luxation récidivante de l'épaule. Lyon Chir 1954; 49: 994-7.

[10] Helfet AF. Coracoid transplantation for recurring dislocation of the shoulder, J Bone Joint Surg 1958; 4: 198-202.

[11] Mead NC, Sweeney HJ. Bristow procedure. Spectator letter. The Spectator Society 1964 .

[12] May VR. A modified Bristow operation for anterior recurrent dislocation of the shoulder. J Bone Joint Surg 1970; 52(5): 1010-6.

[13] Lafosse L, Lejeune E, Bouchard A, et al. The arthroscopic Latarjet procedure for the treatment of anterior shoulder instability. Arthroscopy 2007; 23(11): 1242.e1-5.

[14] Boileau P, Roussanne Y, Bicknell R. Arthroscopic BristowLatarjet-Bankart procedure: the "triple blocking" of the shoulder. In: Boileau P, Ed. Shoulder Concepts 2008. Arthroscopy \&Arthroplasty. France: Sauramps Médical, Montpellier 2008; pp. $87-105$.
[15] Boileau P, Mercier N, Roussanne Y, et al. Arthroscopic BankartBristow-Latarjet procedure: the development and early results of a safe and reproducible technique. Arthroscopy 2010; 26: 1434-50.

[16] Laing PG. The arterial supply of the adult humerus. J Bone Joint Surg Am 1956; 38: 1105-16

[17] Gerber C, Schneeburger AG, Vinh TS. The arterial vascularization of the humeral head: an anatomical study. J Bone Joint Surg Am 1990; 72: 1486-94

[18] Jakob RP, Miniaci A, Anson PS, et al. Four-part valgus impacted fractures of the proximal humerus. J Bone Joint Surg Br 1991; 73: 295-8.

[19] Codman EA. The Shoulder. Rupture of the supraspinatus tendon and other lesions in or about the Subacromial Bursa. Boston MA: Thomas Todd 1934; pp. 285-314.

[20] Neer CS $2^{\text {nd }}$. Displaced proximal humeral fractures - Classification and evaluation. J Bone Joint Surg Am 1970; 52: 1077-89.

[21] Orthopaedic Trauma Association Committee for Coding and Classification. Fracture and dislocation compendium. J Orthop Trauma 1996; 10(1): 1-155.

[22] Fukuda H, Mikasa M. Trends in modern shoulder surgery: personal observations. J Orthop Sci 2007; 12: 4-13.

[23] Neer CS $2^{\text {nd }}$, Brown TH, McLaughlin HL. Fracture of the neck of the humerus with dislocation of the head fragment. Am J Surg 1953; 85: 252-8.

[24] Codman EA. Complete rupture of the supraspinatus tendon. Operative treatment with report of two successful cases. J Shoulder Elbow Surg 2011; 20(3): 347-9.

[25] Smith JG. Pathological appearances of seven cases of injury of the shoulder-joint: with remarks. Lond Med Gaz 1834; 14: 280-5.

[26] McLaughlin HL. Lesions of the musculotendinous cuff of the shoulder: the exposure and treatment of tears with retraction. J Bone Joint Surg 1944; 26: 31-51.

[27] Neer CS, $2^{\text {nd }}$. Anterior acromioplasty for the chronic impingement syndrome in the shoulder. A preliminary report. J Bone Joint Surg Am 1972; 54: 41-50.

[28] Bigliani LU, Morrison DS, April EW. The morphology of the acromion and its relationship to rotator cuff tears. Orthop Trans 1986; 10: 228.

[29] Wuh HCK, Snyder SJ. A modified classification of the supraspinatus outlet view based on the configuration and anatomic thickness of the acromion. Orthop Trans 1992; 16: 767.

[30] Walch G, Boileau F, Noel E, et al. Impingement of the deep surface of the supraspinatus tendon on the posterosuperiorglenoid rim: An arthroscopic study. J Shoulder Elbow Surg 1992; 1(5): 238-45.

[31] Neer CS. Impingement lesions. Clin Orthop1983; 173: 70-7.

[32] Petersson CJ, Gentz CF. Ruptures of the supraspinatus tendon. The significance of distally pointing acromioclavicular osteophytes. Clin Orthop 1983; 174: 143-8

[33] Gwilym SE, Watkins B, Cooper CD, et al. Genetic influences in the progression of tears of the rotator cuff. J Bone Joint Surg Br 2009; 91: 915-7.

[34] WülkerN, Vocke AK. Subacromial disorders. In: Wülker N, Mansat M, Fu FH, Eds. Shoulder Surgery. An Illustrated Textbook. London: Dunitz 2001; pp. 143-86.

[35] Wuelker N, Melzer C, Wirth CJ. Shoulder surgery for rotator cuff tears. Ultrasonographic 3-year follow-up of 97 cases. Acta Orthop Scand 1991; 62: 142-7.

[36] Wirth M, Rockwood CA, Jr. Current concept review: Complications of total shoulder replacement arthroplasty. J Bone Joint Surg Am 1996; 78: 603-16.

[37] Lugli T. Artificial shoulder joint by PEAN 89: the fact of an exceptional intervention and the prosthetic method. Clin Orthop Relat Res 1978; 133: 215-8.

[38] Engelbrecht E, Stellbrink G. Totale Schulter endoprosthese Modell [St. Georg]. Chirurg 1976; 47: 525-30.

[39] Mileti J, Sperling JW, Cofield RH. Monoblock and modular total shoulder arthroplasty for osteoarthritis. J Bone Joint Surg Br 2005; 87: 496-500.

[40] Boileau P, Welcc G. The three-dimensional geometry of the proximal humerus: implications for surgical technique and prosthetic design. J Bone Joint Surg Br 1997; 79: 857-65.

[41] Grammont PM, Baulot E. The classic: Delta shoulder prosthesis for rotator cuff rupture. 1993. Clin Orthop Relat Res 2011; 469: 24223. 
[42] Baulot E, Sirveaux F, Boileau P. Grammont's idea: The story of Paul Grammont's functional surgery concept and the development of the reverse principle. Clin Orthop Relat Res 2011; 469: 2425-31.

[43] Burman MS. Arthroscopy or the direct visualization of joints. An experimental cadaver study. J Bone Joint Surg Am 1931; 13: 66995.

[44] Andren L, Lundberg BJ. Treatment of rigid shoulders by joint distention during arthroscopy. Acta Orthop Scand 1965; 36: 45-53.

[45] Snyder SJ, Karzel RP, Del Pizzo W, et al. SLAP lesion of the shoulder. Arthroscopy 1990; 6: 274-9

[46] Walch G, Liotard JP, Boileau P, et al. Posterosuperior glenoid impingement: another shoulder impingement. Rev Chir Orthop Reparatrice Appar Mot 1991; 77: 571-4

[47] Hedtmann A, Fett H. Shoulder ultrasonography. In: Wülker N, Mansat M, Fu FH, Eds. Shoulder Surgery. An Illustrated Textbook. London: Dunitz 2001; pp. 119-30.
[48] Randelli M, Gambrioli PL, Failoni S, et al. Computed tomography and magnetic resonance imaging. In: Wülker N, Mansat M, Fu FH, Eds. Shoulder surgery. An illustrated textbook. London: Dunitz 2001; pp. 103-17.

[49] Burkhart SS. Expanding the frontiers of shoulder arthroscopy. 11th International Conference on Shoulder and Elbow Surgery. Edinburgh, September 8, 2010.

[50] Isaac C, Gharaibeh B, Witt $\mathrm{M}$, et al. Biologic approaches to enhance rotator cuff healing after injury. J Shoulder Elbow Surg 2012; $21: 181-90$.

[51] Singh JA. Stem cells and other innovative intra-articular therapies for osteoarthritis: what does the future hold? BMC Med 2012; 10: 44.

[52] Singh JA, Mahowald ML, Noorbaloochi S. Intra-articular botulinum toxin A for refractory shoulder pain: a randomized, double-blinded, placebo-controlled trial. Transl Res 2009; 153: 205-16.

(C) Iqbal et al.; Licensee Bentham Open.

This is an open access article licensed under the terms of the Creative Commons Attribution Non-Commercial License (http://creativecommons.org/licenses/by-nc/3.0/) which permits unrestricted, non-commercial use, distribution and reproduction in any medium, provided the work is properly cited. 